\title{
A Class of Continuous Mappings in Ideal Topological Spaces
}

\author{
${ }^{1}$ S.Maragathavalli and ${ }^{2}$ C.R.Parvathy \\ ${ }^{I}$ Department of Mathematics, KarpagamUniversity, CoimbatoreTamilnadu, India \\ ${ }^{2}$ Department of Mathematics, PSGR Krishnammal College for women,Coimbatore, Tamilnadu, India
}

\begin{abstract}
In this paper, we introduce the notions of $I_{r w g}$-continuous maps and $I_{r w g}$-irresolute maps in ideal topological spaces. We investigate some of their properties.

Key words: $I_{r w g}-$ closed set, $I_{r w g}$-continuous maps, $I_{r w g}$-irresoluteness.
\end{abstract}

\section{Introduction}

In 1990, T.R.Hamlett and D.Jankovic[1], introduced the concept of ideals in topological spaces and after that $[2,3,4,5,6]$ several authors turned their attention towards generalizations of various concepts of topology by considering ideal topological spaces.

A non-empty collection I of subsets on a topological space $(X, \tau)$ is called a topological ideal if it satisfies the following two conditions:

(i) If $\mathrm{A} \in \mathrm{I}$ and $\mathrm{B} \subset \mathrm{A}$ implies $\mathrm{B} \in \mathrm{I}$ (heredity)

(ii) If $A \in I$ and $B \in I$, then $A \cup B \in I$ (finite additivity)

By a space $(X, \tau)$, we always mean a topological space $(X, \tau)$. If $A \subset X, c l(A)$ and int(A) will, respectively, denote the closure and interior of $A$ in $(X, \tau)$. Let $(X, \tau, I)$ be an ideal topological space and $A \subset X$. $A^{*}(I, \tau)=\{x$ $\in X / U \cap A \notin I$ for every $U \in \tau(x)\}$, where $\tau(x)=\{U \in \tau: x \in U\}$, is called the local function of A with respect to $\mathrm{I}$ [7] . For every topological space $(\mathrm{X}, \tau, \mathrm{I})$ there exists a topology $\tau^{*}$ finer than $\tau$ defined as $\tau^{*}=\{\mathrm{U} \subseteq \mathrm{X}$ : $\left.\operatorname{cl}^{*}(X-U)=X-U\right\}$. A Kuratowski closure operator $\mathrm{cl}^{*}\left(\right.$.) for topology $\tau^{*}(I, \tau), \mathrm{cl}^{*}(\mathrm{~A})=\mathrm{A} \cup \mathrm{A}^{*}$. Clearly, if $\mathrm{I}=\{\varnothing\}$, then $\operatorname{cl}^{*}(\mathrm{~A})=\operatorname{cl}(\mathrm{A})$ for every subset $\mathrm{A}$ of $\mathrm{X}$. In this paper, we define $\mathrm{I}_{\mathrm{rwg}} \mathrm{g}^{-}$continuous mappings, $\mathrm{I}_{\mathrm{rwg}}-$ irresoluteness in ideal spaces and discuss their properties and characterizations.

\section{Preliminaries}

Definition 2.1:[8]A function $\mathrm{f}:(\mathrm{X}, \tau) \rightarrow(\mathrm{Y}, \sigma)$ is $\mathrm{g}$-continuous if $\mathrm{f}^{-1}(\mathrm{~V})$ is $\mathrm{g}-\operatorname{closed}$ in $(\mathrm{X}, \tau)$ for every closed set $\mathrm{V}$ of $(\mathrm{Y}, \sigma)$.

Definition 2.2: A function $\mathrm{f}:(\mathrm{X}, \tau, \mathrm{I}) \rightarrow(\mathrm{Y}, \sigma)$ is $\mathrm{I}-\mathrm{rg}$-continuous if $\mathrm{f}^{-1}(\mathrm{~V})$ is $\mathrm{I}-\mathrm{rg}-$ open in $(\mathrm{X}, \tau, \mathrm{I})$ for every open set $\mathrm{V}$ in $(\mathrm{Y}, \sigma)$.

Definition 2.3: A function $\mathrm{f}:(\mathrm{X}, \tau, \mathrm{I}) \rightarrow(\mathrm{Y}, \Omega, \mathrm{J})$ is said to be weakly $\mathrm{I}$ - continuous if for each $\mathrm{x} \in \mathrm{X}$ and each open set $\mathrm{V}$ in $\mathrm{Y}$ containing $\mathrm{f}(\mathrm{x})$, there exists an open set $\mathrm{U}$ containing $\mathrm{x}$ such that $\mathrm{f}(\mathrm{U}) \subset \mathrm{cl}^{*}(\mathrm{~V})$.

Definition 2.4[10]: A functionf: $(X, \tau) \rightarrow(Y, \sigma)$ is said to be $I_{s^{*}} g^{-}$continuous if for every $U \in \sigma, f^{-1}(U)$ is $I_{s^{*}} g^{-}$ open in $(\mathrm{X}, \tau, \mathrm{I})$.

Definition 2.5: A functionf: $(\mathrm{X}, \tau, \mathrm{I}) \rightarrow(\mathrm{Y}, \sigma)$ is $*$-continuous if $\mathrm{f}^{-1}(\mathrm{~A})$ is $*$ - closed in $\mathrm{X}$ forevery closed set $\mathrm{A}$ in $\mathrm{Y}$.

Lemma 2.6[9]: Let $(X, \tau, I)$ be an ideal topological space and $A \subset X$. If $A \subset A^{*}$, then $A^{*}=\operatorname{cl}\left(A^{*}\right)=\operatorname{cl}(A)=\operatorname{cl}^{*}(A)$. Lemma 2.7: If $U$ is open and $A$ is $I_{r w g}$ open, then $U \cap A$ is $I_{r w g}-$ open.

\section{Regular Weakly Generalized Continuous Mappings In Ideal Topological Spaces}

Definition 3.1: A function $\mathrm{f}:(\mathrm{X}, \tau, \mathrm{I}) \rightarrow(\mathrm{Y}, \sigma)$ is said to be $\mathrm{I}_{\mathrm{rwg}}$-continuous if $\mathrm{f}^{-1}(\mathrm{~V})$ is $\mathrm{I}_{\mathrm{rwg}}$-closed in $(\mathrm{X}, \tau, \mathrm{I})$ for every closed set $\mathrm{V}$ in $(\mathrm{Y}, \sigma)$.

Theorem 3.2:A function $\mathrm{f}:(\mathrm{X}, \tau, \mathrm{I}) \rightarrow(\mathrm{Y}, \sigma)$ is $\mathrm{I}_{\mathrm{rwg}}$-continuous if and only if $\mathrm{f}^{-1}(\mathrm{~V})$ is $\mathrm{I}_{\mathrm{rwg}}$-open in $(\mathrm{X}, \tau$, I) for every open set $\mathrm{V}$ in $(\mathrm{Y}, \sigma)$.

Proof: Let $\mathrm{V}$ be an open set in $(\mathrm{Y}, \sigma)$ and $\mathrm{f}:(\mathrm{X}, \tau, \mathrm{I}) \rightarrow(\mathrm{Y}, \sigma)$ be $\mathrm{I}_{\mathrm{rwg}}$-continuous. Then $\mathrm{V}^{\mathrm{c}}$ is closed in $(\mathrm{Y}, \sigma)$ and $\mathrm{f}^{-1}\left(\mathrm{~V}^{\mathrm{c}}\right)$ is $\mathrm{I}_{\mathrm{rwg}} \mathrm{g}^{-}$closed in $(\mathrm{X}, \tau, \mathrm{I})$. But $\mathrm{f}^{-1}\left(\mathrm{~V}^{\mathrm{c}}\right)=\left(\mathrm{f}^{-1}(\mathrm{~V})\right)^{\mathrm{c}}$ and so $\mathrm{f}^{-1}(\mathrm{~V})$ is $\mathrm{I}_{\mathrm{rwg}}$-open in $(\mathrm{X}, \tau, \mathrm{I})$.

Conversely, suppose that $\mathrm{f}^{-1}(\mathrm{~V})$ is $\mathrm{I}_{\mathrm{rwg}}$-open in $(\mathrm{X}, \tau, \mathrm{I})$ for each open set $\mathrm{V}$ in $(\mathrm{Y}, \sigma)$. Let $\mathrm{F}$ be a closed set in (Y, $\sigma)$. Then $\mathrm{F}^{\mathrm{c}}$ is open in $(\mathrm{Y}, \sigma)$ and by hypothesis $\mathrm{f}^{-1}\left(\mathrm{~F}^{\mathrm{c}}\right)$ is $\mathrm{I}_{\mathrm{rwg}}-$ open in $\left(\mathrm{X}, \tau\right.$, I). Since $\mathrm{f}^{-1}\left(\mathrm{~F}^{\mathrm{c}}\right)=\left(\mathrm{f}^{-1}(\mathrm{~F})\right)^{\mathrm{c}}$, we have $\mathrm{f}^{-1}\left(\mathrm{~F}^{\mathrm{c}}\right)$ is $\mathrm{I}_{\mathrm{rwg}}$-closed in $(\mathrm{X}, \tau, \mathrm{I})$ and so $\mathrm{f}$ is $\mathrm{I}_{\mathrm{rwg}}$-continuous.

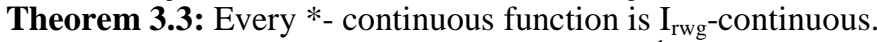

Proof: Let $\mathrm{V}$ be a closed set in $(\mathrm{Y}, \sigma)$. Then $\mathrm{f}^{-1}(\mathrm{~V})$ is $*$-closed in $(\mathrm{X}, \tau, \mathrm{I})$ because $\mathrm{f}$ is * continuous in $\mathrm{X}$. Since every $*$ - closed set is $\mathrm{I}_{\mathrm{rwg}}-$ closed, $\mathrm{f}^{-1}(\mathrm{~V})$ is $\mathrm{I}_{\mathrm{rwg}}-$ closed in $(\mathrm{X}, \tau, \mathrm{I})$. Therefore $\mathrm{f}$ is $\mathrm{I}_{\mathrm{rwg}}$-continuous.

The converse of the above theorem need not be true as seen from the following example. 
Example 3.4: $X=\{1,2,3\}, \tau=\{\varnothing, X,\{1\},\{2,3\}\}, I=\{\varnothing,\{3\}\}$ and $\sigma=\{\varnothing, X,\{1,3\}\}$.

The identity map $\mathrm{f}:(\mathrm{X}, \tau, \mathrm{I}) \rightarrow(\mathrm{Y}, \sigma)$ is $\mathrm{I}_{\mathrm{rwg}}$-continuous but not $*$ - continuous.

Theorem 3.5: Every continuous function is $\mathrm{I}_{\mathrm{rwg}}$-continuous.

Proof: Let $\mathrm{f}$ be a continuous function and $\mathrm{V}$ be a closed set in $(\mathrm{Y}, \sigma)$. Then $\mathrm{f}^{-1}(\mathrm{~V})$ is closed in $(\mathrm{X}, \tau$, I). Since every closed set is * -closed and hence $\mathrm{I}_{\mathrm{rwg}}-\operatorname{closed}, \mathrm{f}^{-1}(\mathrm{~V})$ is $\mathrm{I}_{\mathrm{rwg}}-$ closed in $(\mathrm{X}, \tau, \mathrm{I})$. Therefore, $\mathrm{f}$ is $\mathrm{I}_{\mathrm{rwg}} \mathrm{r}^{-}$ continuous.

The converse of the above theorem need not be true as seen from the following example.

Example 3.6: Let $X=\{1,2,3\}, \tau=\{\varnothing, X,\{1\},\{2,3\}\}, I=\{\varnothing,\{3\}\}$ and $\sigma=\{\varnothing, X,\{1\}\}$.

Define $\mathrm{f:}(\mathrm{X}, \tau, \mathrm{I}) \rightarrow(\mathrm{Y}, \sigma)$ as $\mathrm{f}(1)=2, \mathrm{f}(2)=1, \mathrm{f}(3)=3$. Then $\mathrm{f}$ is $\mathrm{I}_{\text {rwg }}$-continuous but not continuous.

Remark 3.7: The above relationships are shown in the following diagram:

Continuity $\Rightarrow *$ - Continuity $\Rightarrow \mathbf{I}_{\mathrm{rwg}}$-continuity

Definition 3.8:[10] An ideal topological space $(\mathrm{X}, \tau, \mathrm{I})$ is said to be $\mathrm{T}$-dense if every subset of $\mathrm{X}$ is $*$-dense in itself.

Theorem 3.9: Let $(\mathrm{X}, \tau, \mathrm{I})$ be $\mathrm{T}$-dense. Then for a function $\mathrm{f}:(\mathrm{X}, \tau, \mathrm{I}) \rightarrow(\mathrm{Y}, \sigma)$ the following statements are equivalent:

(1) $\mathrm{f}$ is $\mathrm{I}_{\mathrm{rwg}}$-continuous.

(2) For each $\mathrm{x} \in \mathrm{X}$ and each open set $\mathrm{V}$ in $\mathrm{Y}$ with $\mathrm{f}(\mathrm{x}) \in \mathrm{V}$, there exists an $\mathrm{I}_{\mathrm{rwg}}$-open set $\mathrm{U}$ containing $\mathrm{x}$ such that $\mathrm{f}(\mathrm{U}) \subset \mathrm{V}$.

(3) For each $\mathrm{x} \in \mathrm{X}$ and each open set $\mathrm{V}$ in $\mathrm{Y}$ with $\mathrm{f}(\mathrm{x}) \in \mathrm{V}, \mathrm{f}^{-1}(\mathrm{~V})$ is an $\mathrm{I}_{\mathrm{rwg}}$-open neighborhood of $\mathrm{x}$.

Proof: $(1) \Rightarrow(2)$ Let $x \in X$ and let $V$ be an open set in $Y$ such that $f(x) \in V$. Since $f$ is $I_{r w g}$-continuous, $f^{-1}(V)$ is an $\mathrm{I}_{\mathrm{rwg}}$-open in $\mathrm{X}$. By taking $\mathrm{U}=\mathrm{f}^{-1}(\mathrm{~V})$, we have $\mathrm{x} \in \mathrm{U}$ and $\mathrm{f}(\mathrm{U}) \subset \mathrm{V}$.

(2) $\Rightarrow$ (3) Let $\mathrm{V}$ be an open set in $\mathrm{Y}$ and let $\mathrm{f}(\mathrm{x}) \in \mathrm{V}$.Then by (2), there exists an $\mathrm{I}_{\mathrm{rwg}}$ - open set $\mathrm{U}$ containing $\mathrm{x}$ such that $\mathrm{f}(\mathrm{U}) \subset \mathrm{V}$. So $\mathrm{x} \in \mathrm{U} \subset \mathrm{f}^{-1}(\mathrm{~V})$. Hence $\mathrm{f}^{-1}(\mathrm{~V})$ is an $\mathrm{I}_{\mathrm{rwg}}$-open neighborhood of $\mathrm{x}$.

(3) $\Rightarrow$ (1) Let $\mathrm{V}$ be an open set in $\mathrm{Y}$ and let $\mathrm{f}(\mathrm{x}) \in \mathrm{V}$. Then by (3) $\mathrm{f}^{-1}(\mathrm{~V})$ is an $\mathrm{I}_{\mathrm{rwg}}$-open neighborhood of $\mathrm{x}$. Thus for each $x \in f^{-1}(V)$, there exists an $I_{r w g}$-open set $U_{x}$ containing $x$ such that $x \in U_{x} \subset f^{-1}(V)$. Hence $f^{-1}(V)=$ $\bigcup_{x \in f^{-1}(V)} \bigcup_{x}$ and so $\mathrm{f}^{-1}(\mathrm{~V})$ is an $\mathrm{I}_{\mathrm{rwg}}$-open in $\mathrm{X}$.

Theorem 3.10: Let $\mathrm{f}:(\mathrm{X}, \tau, \mathrm{I}) \rightarrow(\mathrm{Y}, \sigma, \mathrm{J})$ be a function and $\left\{\mathrm{U}_{\alpha}: \alpha \in \nabla\right\}$ be an open cover of a T-dense space $X$. If the restriction $\mathrm{f} \mid \mathrm{U}_{\alpha}$ is $\mathrm{I}_{\mathrm{rwg}}$-continuous for each $\alpha \in \nabla$, $\mathrm{f}$ is $\mathrm{I}_{\mathrm{rwg}}$-continuous.

Proof: Suppose V is an arbitrary open set in $(\mathrm{Y}, \sigma, \mathrm{J})$. Then for each $\alpha \in \nabla$, we have $\left(\mathrm{f} \mid \mathrm{U}_{\alpha}\right)^{-1}(\mathrm{~V})=\mathrm{f}^{-1}(\mathrm{~V}) \cap \mathrm{U}_{\alpha}$. Because $\mathrm{f} \mid \mathrm{U}_{\alpha}$ is $\mathrm{I}_{\mathrm{rwg}}$-continuous, therefore $\mathrm{f}^{-1}(\mathrm{~V}) \cap \mathrm{U}_{\alpha}$ is $\mathrm{I}_{\mathrm{rwg}}$ - open set in $\mathrm{X}$ for each $\alpha \in \nabla$. Since for each $\alpha \in \nabla$, $\mathrm{U}_{\alpha}$ is open in $\mathrm{x}$, by [9 Theorem 5] $\mathrm{f}^{-1}(\mathrm{~V}) \cap \mathrm{U}_{\alpha}$ is $\mathrm{I}_{\mathrm{rwg}}$-open set in X. Now since $\mathrm{X}$ is T-dense, $\bigcup_{\alpha \in V} \mathrm{f}^{-1}(\mathrm{~V}) \cap \mathrm{U}_{\alpha}=$ $\mathrm{f}^{-1}(V)$ is $\mathrm{I}_{\mathrm{rwg}}$ - open in $\mathrm{X}$. This implies $\mathrm{f}$ is $\mathrm{I}_{\mathrm{rwg}}$-continuous.

Theorem 3.11: If $(\mathrm{X}, \tau, \mathrm{I})$ is $\mathrm{T}$-dense space and $\mathrm{f}:(\mathrm{X}, \tau, \mathrm{I}) \rightarrow(\mathrm{Y}, \sigma)$ is $\mathrm{I}_{\mathrm{rwg}}$-continuous, then graph function $\mathrm{g}: \mathrm{X} \rightarrow \mathrm{X} \times \mathrm{Y}$, defined by $\mathrm{g}(\mathrm{x})=(\mathrm{x}, \mathrm{f}(\mathrm{x}))$ for each $\mathrm{x} \in \mathrm{X}$, is $\mathrm{I}_{\mathrm{rwg}}$-continuous.

Proof: Let $\mathrm{x} \in \mathrm{X}$ and $\mathrm{W}$ be any open set in $\mathrm{X} \times \mathrm{Y}$ containing $\mathrm{g}(\mathrm{x})=(\mathrm{x}, \mathrm{f}(\mathrm{x}))$. Then there exists a basic open set $\mathrm{U} \times \mathrm{V}$ such that $\mathrm{g}(\mathrm{x}) \subset \mathrm{U} \times \mathrm{V} \subset \mathrm{W}$. Since $\mathrm{f}$ is $\mathrm{I}_{\mathrm{rwg}}$-continuous, there exists an $\mathrm{I}_{\mathrm{rwg}} \mathrm{g}^{-}$open set $U_{1}$ in $X$ containing $\mathrm{x}$ such that $\mathrm{f}\left(\mathrm{U}_{1}\right) \subset \mathrm{V}$. By Lemma $2.7 \mathrm{U}_{1} \cap \mathrm{U}$ is $\mathrm{I}_{\mathrm{rwg}}$ - open in $\mathrm{X}$ and we have $\mathrm{x} \in \mathrm{U}_{1} \cap \mathrm{U} \subset \mathrm{U}$ and $\mathrm{g}\left(\mathrm{U}_{1} \cap \mathrm{U}\right) \subset \mathrm{U}$ $\times \mathrm{V} \subset \mathrm{W}$. Since $\mathrm{X}$ is T-dense, therefore Theorem 3.9, $\mathrm{g}$ is $\mathrm{I}_{\mathrm{rwg}}$-continuous.

Definition 3.12: For a function $\mathrm{f}:(\mathrm{X}, \tau, \mathrm{I}) \rightarrow(\mathrm{Y}, \sigma)$, the subset $\{(\mathrm{x}, \mathrm{f}(\mathrm{x})): \mathrm{x} \in \mathrm{X}\} \subset \mathrm{X} \times \mathrm{Y}$ is called the graph of $f$ and is denoted by $G(f)$.

Theorem 3.13: Let $\mathrm{f}:(\mathrm{X}, \tau, \mathrm{I}) \rightarrow(\mathrm{Y}, \sigma)$ be a function and $\mathrm{g}: \mathrm{X} \rightarrow \mathrm{X} \times \mathrm{Y}$ be the graph function of $\mathrm{f}$. If $\mathrm{g}$ is $\mathrm{I}_{\mathrm{rwg}^{-}}$ continuous, then $\mathrm{f}$ is $\mathrm{I}_{\mathrm{rwg}}$-continuous.

Proof: Suppose that $g$ is $I_{r w g}$-continuous. Let $x \in X$ and $V$ be any open set of $Y$ containing $f(x)$. Then $X \times V$ is open in $X \times Y$ and $I_{r w g}$-continuity of $g$, then exists $U \in I_{r^{\prime w g}}-$ open of $X$ containing $x$ such that $g(U) \subset X \times V$. Therefore we obtain $\mathrm{f}(\mathrm{U}) \subset \mathrm{V}$. Hence $\mathrm{f}$ is $\mathrm{I}_{\mathrm{rwg}}$-continuous.

Remark 3.14: The composition of two $I_{\text {rwg }}$-continuous maps need not be $I_{r w g}$-continuous as seen from the following example.

Example 3.15: Let $\mathrm{X}=\mathrm{Y}=\mathrm{Z}=\{1,2,3,4\}, \tau=\{\varnothing, \mathrm{X},\{1\},\{1,2,3\}\}$ and $\sigma=\{\varnothing, \mathrm{Y},\{3\}\}$

$\Omega=\{\varnothing, \mathrm{Z},\{2,4\}\}, \mathrm{I}=\{\varnothing,\{1\},\{2\},\{1,2\}\}, \mathrm{J}=\{\varnothing,\{3\}\} . \mathrm{f:}(\mathrm{X}, \tau, \mathrm{I}) \rightarrow(\mathrm{Y}, \sigma, \mathrm{J})$ and

$\mathrm{g}:(\mathrm{Y}, \sigma, \mathrm{J}) \rightarrow(\mathrm{Z}, \Omega)$ be identity maps. Then the maps $\mathrm{f}$ and $\mathrm{g}$ are $\mathrm{I}_{\mathrm{rwg}}$-continuous but $\mathrm{g}$ o $\mathrm{f}$ is not $\mathrm{I}_{\mathrm{rwg}}$-continuous. 


\section{Regular Weakly Generalized Irresoluteness In Ideal Topological Spaces}

Definition 4.1 : A function $\mathrm{f}:(\mathrm{X}, \tau, \mathrm{I}) \rightarrow(\mathrm{Y}, \sigma, \mathrm{J})$ is said to be $\mathrm{I}_{\mathrm{rwg}}$-irresolute if $\mathrm{f}^{-1}(\mathrm{~V})$ is $\mathrm{I}_{\mathrm{rwg}}$-closed in $(\mathrm{X}, \tau, \mathrm{I})$ for every $\mathrm{I}_{\mathrm{rwg}}$-closed set $\mathrm{V}$ in $(\mathrm{Y}, \sigma, \mathrm{J})$.

Theorem4.2: Every $\mathrm{I}_{\mathrm{rwg}}$-irresolute function is $\mathrm{I}_{\mathrm{rwg}}$-continuous.

Proof: Suppose $\mathrm{f}:(\mathrm{X}, \tau, \mathrm{I}) \rightarrow(\mathrm{Y}, \sigma, \mathrm{J})$ is $\mathrm{I}_{\mathrm{rwg}}$-irresolute. Let $\mathrm{V}$ be a closed in $\mathrm{Y}$ which is $\mathrm{I}_{\mathrm{rwg}}$-closed then $\mathrm{f}^{-1}(\mathrm{~V})$ is $I_{r w g}$-closed in $X$. Hence $f$ is $I_{r w g}$-continuous.

Converse of the theorem is not true as seen from the following example.

Example 4.3: Let $X=Y=\{a, b, c\}, \tau=\{\varnothing, X,\{a\},\{b\},\{a, b\}\}, I=\{\varnothing,\{c\}\}, \sigma=\{\varnothing,\{a, b\}\}, J=\{\varnothing,\{b\}\}$. The identity function is $\mathrm{I}_{\mathrm{rwg}}$-continuous but not $\mathrm{I}_{\mathrm{rwg}}$-irresolute. Since the $\mathrm{I}_{\mathrm{rwg}}$-closed sets in $\mathrm{Y}$ are the power set of $\mathrm{Y}$ and $\mathrm{I}_{\mathrm{rwg}}$-closed sets of $X$ are $\{\varnothing, X,\{c\},\{a, b\},\{a, b\},\{b, c\}\}$.

Theorem 4.4: A function $\mathrm{f}:(\mathrm{X}, \tau, \mathrm{I}) \rightarrow(\mathrm{Y}, \sigma, \mathrm{J})$ is $\mathrm{I}_{\mathrm{rwg}}$-irresolute if and only if the inverse mage of every $\mathrm{I}_{\mathrm{rwg}^{-}}$ open in $(\mathrm{Y}, \sigma, \mathrm{J})$ is $\mathrm{I}_{\mathrm{rwg}}$-open in $(\mathrm{X}, \tau, \mathrm{I})$.

Theorem 4.5: If function $\mathrm{f}:(\mathrm{X}, \tau, \mathrm{I}) \rightarrow(\mathrm{Y}, \sigma, \mathrm{J})$ is $\mathrm{I}_{\mathrm{rwg}}$ - irresolute and $\mathrm{g}:(\mathrm{Y}, \sigma, \mathrm{J}) \rightarrow(\mathrm{Z}, \eta)$ is *-continuous then $\mathrm{g} \circ \mathrm{f}:(\mathrm{X}, \tau, \mathrm{I}) \rightarrow(\mathrm{Z}, \eta)$ is $\mathrm{I}_{\mathrm{rwg}}$-continuous.

Proof: Let $V$ be any closed set of $(\mathrm{Z}, \eta)$. Then $\mathrm{g}^{-1}(\mathrm{~V})$ is * - closed in $(\mathrm{Y}, \sigma, \mathrm{J})$. Therefore $\mathrm{f}^{-1}\left(\mathrm{~g}^{-1}(\mathrm{~V})=(\mathrm{g} \circ \mathrm{f})^{-1}(\mathrm{~V})\right.$ is $\mathrm{I}_{\mathrm{rwg}}$ - closed in $(\mathrm{X}, \tau, \mathrm{I})$, since every *- closed set is $\mathrm{I}_{\mathrm{rwg}}$ - closed.

Hence $\mathrm{g} \circ \mathrm{f}$ is $\mathrm{I}_{\mathrm{rwg}}$-continuous.

\section{References}

[1] T. R. Hamlett and D. Jankovic, Compactness with respect to an ideal, Boll. Un. Mat. Ita.,(7), 4-B, 849-861. 1990.

[2] E. Hayashi. Topologies defined by local properties. Math.Ann., 1964, 156: 205-215

[3] T. R. Hamlett and D. Jankovic, Ideals in topological spaces and the set operator, Boll.Un. Mat. Ita, 7, 863-874. 1990.

[4] T. R. Hamlett and D. Jankovic, Ideals in General Topology and Applications (Midletown,CT, 1988), 115-125, Lecture Notes in Pure and Appl. Math. Dekker, New York, 1990.

[5] T. R. Hamlett and D. Jankovic, Compatible extensions of ideals, Boll. Un. Mat. Ita., 7,453- 465, 1992.

[6] D. Jankovic and T. R. Hamlett, New topologies from old via ideals, Amer. Math. Monthly 97, 295-310, 1990.

[7] Kuratowski K. topology, Vol I, Academic Press, New York,1966.

[8] N.Levine, Semi-open sets and semi-continuity in topological spaces, Amer.Math.Monthly,70(1963),36-41.

[9] R. Vaidyanathaswamy, Set Topology, Chelsea Publishing Company, 1946.

[10] M.Khan and T.Noiri, On $\mathrm{I}_{\mathrm{S}^{*} \mathrm{~g}}$ - Continuous functions in ideal topological spaces, European Journal of Pure and applied Mathematics,ISSN Volume 4, Number 3(2011),237-243 ISSN 1307-5543. 